\title{
A CRITICAL REVIEW OF DEVELOPMENTS IN THE PYROLYSIS OF AUTOMOTIVE SHREDDER RESIDUE
}

\author{
Marie K. Harder* and Osric Tening Forton \\ Waste \& Energy Research Group (WERG), Faculty of Science and Engineering. \\ University of Brighton, Lewes Road. Brighton, BN2 4GJ, UK \\ *Corresponding author. Tel.: +44 1273 642539; fax: +44 1273642285. \\ E-mail address: m.k.harder@brighton.ac.uk (M.K. Harder).
}




\begin{abstract}
Worldwide, automotive shredder residue (ASR) is considered an increasingly problematic mixture of materials that needs the development of a processing solution. Pyrolysis is a process that has many advantages to offer, but despite many studies and developments in recent years at various levels of commercialisation, it is still generally considered unproven for this purpose.
\end{abstract}

This paper critically considers developmental work published in the field, presents new results, and suggests that a major reason for the lack of development is the complexity of the landscape created by strong, competing, economic, legislative, environmental and commercial drivers, which in turn make it unclear which products and processes are optimal. This is made doubly complex by the natural variation in the material composition of ASR, with contaminants that can critically affect its potential fate to anywhere in the range from hazardous waste, to energy source, to useful raw material for major cement or steel industries.

New data on critical factors such as levels of chlorine and metals in raw and pyrolysed ASR are presented, alongside a much-needed summary of previously published values from references that are often difficult to source. The summaries emphasise the variation in the material, but also indicate rough boundaries for values, which are needed for the design of any potentially successful process. 
It is suggested that the heterogeneity seen across ASR types implies that specialised processing of SR on its own is unlikely. It is pointed out that small-scale processes that could be suitable for local requirements should be considered for development as they could be able to optimise a process sufficiently to make it viable, e.g. specialised local waste streams of paper pulp and a particular fraction of SR.

Keywords: ELV, end-of-life vehicle, ASR, automotive shredder residue, pyrolysis, heavy metals, chlorine, cement, SR, composition, contamination

\section{Introduction}

In the waste management industry, pyrolysis and gasification are generally considered emerging technologies $[1,2]$. Although well known as in arenas such as the conversion of coal into town gas, they have been slow to be taken up in waste management. The apparently simple shift from taking in homogenous, well-characterised traditional feedstocks to heterogeneous, variable waste stream feedstocks has proven to be not so simple. This has been a significant factor preventing demonstrator plants from moving to successful commercial status. 
Shredder residue has all the problematic characteristics of a complex waste stream which make it difficult to process. Although large, constant supplies are available [3-12] to provide a secure supply, shredder residue contains proportions of sulphur, chlorine [13], heavy metals [14-16] and contaminant oils [17] from elastomers, PVC, metals and car fluids respectively which can vary significantly from hour to hour, requiring demanding design features the pyrolysis process. Not only the presence of these materials but the fluctuations in their levels in the feed [18-21] provides many challenges, themselves due to variations of types and ages of vehicles, additional scrap feed from white goods and light iron, $[6,21-24]$ and even different operating conditions at contractors supplying the feed. Adding to these challenges are the highly variable moisture content $[12,18,21,22$, $24]$ and energy content $[6,7,25-29]$ of SR. Full information on all of these parameters is needed for the design of appropriate thermal processes. Summaries of their published values are thus provided in this paper.

The pressure to achieve commercial processes to deal with such complex waste feedstock is growing year by year. This is especially true for shredder residues (SR) because it is increasingly considered unsuitable for landfill disposal [30, 31]. There are several significant drivers set up to encourage developments in pyrolysis SR - players in political, policy-making, financial, consultancy, investment banking and technological fields have all worked to assist the development of useful pyrolysis processes. However, the very fact that these drivers come from such a wide range of fields makes it difficult for process developers to have an overview of the entire ASR landscape at any given time. Much of 
the needed information is scattered and difficult to obtain, not being in easily accessible journals.

This paper aims to assist further developments by providing a review of current technical developments in pyrolysis processes for ASR, and fully contextualizing them in terms of current legislative drivers, various national drivers, practical constraints, feedstock composition and variability, and competing technologies. It summarises key data on ASR and its pyrolysis, and lists sources of information on various developments.

\section{Variations in the physical characteristics of (A)SR}

A characteristic of all fuels, which is usually assumed, is basic homogeneity. Any potential pyrolysis process for shredder residue (SR), however, is a heterogeneous mixture of all the materials found in cars, ovens, etc., and this heterogeneity needs to be taken into account when designing fuels from it. Shredder residue is produced when ELVs and other scrap are shredded into pieces the size of an orange, and the metal chunks (70\%) removed from the rest, usually with an air cyclone, for steel recycling [9, $11,18,32,33]$. The remaining $30 \%$ is usually run through a trommel for size separation, and the larger pieces processed further to remove more metals (5\%). The fraction which is lifted by the cyclone is called light ASR, frag, fluff or flock. Heavier pieces mixed in with the last set of metals removed is sometimes labelled 'heavy SR'; not all process produce it. 
Most operators depollute ELVs before they are shredded, by removing fluids, batteries, wheels and tyres $[31,34,35]$. Variations in such practices can greatly vary characteristics of the ASR, including levels of contamination in the subsequent SR produced.

Table 1 provides a summary of reported (A)SR compositions. Note the greatly differing categorisation and values. Results will vary depending on the feed (different fractions of ELVs; light iron, white goods such as cookers; different types of ELVs (such as trucks, buses, cars of differing ages), the efficiency of the metal extraction systems, wear of the trommel sieves, variations in the cyclone forces. Further variation is introduced when trying to visually classify such waste $[12,18,22,23,36]$; as over $50 \%$ of SR usually has a particle size of less than $30 \mathrm{~mm}$, this is a significant contributor. However, this data is not usually critical to pyrolysis process design, unlike the other quantities below, so unnecessarily detailed efforts have not been made to improve its precision.

\section{[INSERT TABLE 1]}

The energy content of (A)SR is crucial to the design of a thermal process for it, and a summary of reported values is given in Table 2 . Some processes may be designed for minimal energy production (focusing instead on materials recovery from the char) [37] in which case it might be preferred to remove the most calorific components e.g. elastomers and polymers. Conversely, some plant may be required to first separate off the glass component, in order to achieve a higher specific calorific content. 
Table 1 shows that although there is a general consensus of values from 20-30 MJ per kg, there is still significant variation. This is not unexpected with varying car types (modern cars have more plastics) and feed mixes. Note that these figures are usually for dried materials and thus unlikely to take into account the huge variation of moisture content found in SR due to artificial dampening of SR as a fire precaution and weather conditions $[12,18,21,22,24]$.

\section{[INSERT TABLE 2]}

All pyrolysis processes produce solid, liquid and gaseous products $[38,39]$ whose ratios and character depend not only on the feed (e.g. fractions of plastics versus inorganic) but also on the temperature, residence time and carrier gases used [7, 40, 41]. There is a great range of variations possible, and the values used in a given process design must be chosen depending on which products it is optimising for. However, there is a general envelope of values that are possible, as indicated in Table 3 where reported published values are summarised; the char produced is rarely outside the range $33-68 \%$ by weight. These high values indicate that pyrolysis has good potential for material recovery compared to processes such as incineration where the hydrocarbons are burned off important when designing to meet the material recycling targets [31] in the ELV Directive

Processes for the pyrolysis of ASR could specifically be designed to maximise the gaseous products, e,g, for fuel use, but then there will be other considerations such as larger chambers for collection or combustion, and large gas cleaning units. If the process 
are designed instead to preferentially produce oils or liquid fuels, a large space and capital investment will be needed for the required distillation plant.

\section{[INSERT TABLE 3]}

Pyrolysis processes could similarly focus on material recovery as a key design requirement in which case the char would be processed to remove any remaining metals in it, e.g. those which were originally attached to polymeric materials. In some cases the carbon in the char will be targeted for recovery; in others the entire char will be considered as a substitute fuel or raw material. For these purposes it is important to know what the level of remaining metals is in the char, as these will now be considered 'contamination' and are likely to be problematic. Industries which can potentially make use of pyrolysis char include iron, steel and cement [14, 15, 42-45]. However, they have restrictions on the presence of some metals, and chlorine $[14,15]$. Table 4 provides a summary of published levels for some metals in (A)SR pyrolysed char.

\section{[INSERT TABLES 4,5]}

If pyrolysed char is not recycled but sent for disposal to landfill, there is a possibility that it will not meet requirements for threshold values of leaching of the contaminant metals. This problem can be avoided when designing an ASR pyrolysis process by using the large amounts of waste heat available to vitrify the char. Several processes incorporate this idea.

For the cement industry, the level of contaminant metals remaining in ASR char is generally excessive $[13-15,42,43]$. Chlorine levels are also a problem - mainly from PVC and other plastics. One way to reduce them is to remove contributions downstream, 
i.e. in or before the shredding process. For this it is useful to know the metal and chlorine content of the raw ASR, and published values are thus summarised in Table 6.

It is particularly important to have good data on the chlorine levels [13] because, especially in the presence of ample amounts of reaction water, HCL is produced which reacts with the linings of the pyrolyser. Chlorine levels will also affect the chlorine contamination levels in the gases and oils produced, which can completely rule out many uses of them.

Yet another reason to be aware of metal and chlorine contamination levels in raw ASR is that these increasingly dictate whether it can be landfilled or not. This then becomes an important driver for new thermal processes. For example, California State thresholds have been set at 1000ppm for lead in raw SR [46], and UK suggested values are 5000ppm [47]. If raw ASR cannot meet those, then a thermal process of some kind becomes necessary, to provide an alternative disposal route.

\section{The Evolution of Pyrolysis Processes for (A)SR}

A review of technologies for the pyrolysis and gasification of (most) wastes worldwide was available as a commercial publication in 2002 [48]. In 2004 an excellent review of pyrolysis and gasification processes for MSW was published [1]. Both indicated a number of processes that had the potential to develop into commercially useful options 
for SR. Of these, several years later, only one is now considered to be fully commercial the Ebara plant in Japan [48-50]. Ebara co-processes SR with sewerage sludge (70/30) at around 100,000 tonnes per year using gasification followed by vitrification of the residue in order to produce an 'inert' product.

Only three other pyrolysis processes are classified as semi- or fully-commercial, and which clearly specify that they can handle ASR as a feed. They are the PKA process, the Pyromelt Process (Lurgi Ensorgung), and the TWR process (Siemens; Schwel-Brenn; TWR/Mitsui). Each is shown below in Figs. 1-4 (prepared from information in [1]). The fourth process shown, Schwarze Pumpe (SVZ;Global Energy) [13], uses gasification, producing methanol as a fuel, and is at a demonstrator level only.

\section{[INSERT FIG. 1 - 4]}

These are the processes that have survived the last few years of evolution, and it is interesting to note that have developed ways of dealing with some of the difficult characteristics of ASR in the same manner. For example, they all mix ASR feed with other wastes to regulate the variations in energy content and material. They also all make significant use of the gases given off - even in the pyrolysis process. And they all obtain significant material recovery by post-processing the char. Several make use of the available energy to resolve the difficulty of dealing with remaining char by vitrifing it after making use of the carbon energy. Although this may look like a neat final solution it should be remembered that vitrification temperatures are so high that it is, in effect, an expensive way to manufacture glass. 
Commercial viability is not assisted by many of these solutions. For example, some require pre-shredding to small particle size, which, like the vitrification, has significant associated financial and energy costs. Handling of the waste is also important; it will make a considerable difference in costs if $\mathrm{SR}$ has to be transported to a thermal processing plant, as opposed to the plant being constructed alongside the shredding site. It will also prove considerably more viable if the energy produced can be utilised immediately on site or by an adjacent user, than it being utilised elsewhere.

These recent developments suggest that in the future there will be likely a mixture of ASR with other wastes such as MSW and biomasses, in large facilities, or alongside power stations or cement / steel industries where the char and energy can directly replace fossil fuels. However, there is still a niche market for smaller that can take advantage of opportunities peculiar to the shredding industry. For example, some shredding operators may have one site in their portfolio with enough space to put a plant to convert pyrolysis liquids to diesel, which could be used to fuel their shredding plant at all sites. Shredding sites are sometimes located adjacent to big energy or steam users, or to sub-stations capable of allowing inputted electricity onto a grid system. Such niche market processes are likely to need to meet the general requirements of smaller shredder operators, who come from a scrap metal background and might prefer to deal with local companies they have a history with. They will want very robust plant that will not break down, which have a throughput of around 20 tonnes per day, and where the residence time is short. Such sites will not want the health and safety issues associated with raising steam, and are unlikely to have space for huge combustion chambers. A small stack or none would 
be preferred to avoid lengthy planning requests. The production of a fuel like off-road diesel that is immediately useful to the operator would be a bonus for those sites that do have the space for combustion.

Such individually designed plant would have the distinct advantage of being optimised to the specific type of feed and waste at that site. For example, it might be decided to concentrate the plastics in SR into one feed which is then mixed with another local and constant stream like paper pulp for additional income, designed for gasification and disposal. The remaining SR will have much less energy density and could be put into a small parallel process designed primarily for materials recovery. Similarly, if special preprocessing is required to make the local process viable, such as reducing the PVC content, a shredding operator may find his own way to do this efficiently. Such small scale development will also safeguard local operators from being tied in to agreements with the large companies running centralised SR processing plant. Such companies could otherwise effectively monopolise the market for the SR produced, putting the investment of the small scale operator at risk.

\section{Competing environmental, legislative, and commercial}

\section{drivers}

\subsection{Drivers initiated by legislation}

Although the main drivers for treating ASR come from environmental legislation, their knock-on effects are complex and often even more significant. This is illustrated below. 
The European End of Life Vehicles Directive [2000/53/EC] [31] requires that 95\% of ELV waste is reused by 2015 , with only $10 \%$ of this recovered through energy. The European Waste Incineration Directive [2000/76/EC] [51] requires waste with more than $1 \%$ halogenated organic substances to comply with specific operational conditions to destroy PCDD/Fs by 2015 - but waste with a net calorific value greater than $30 \mathrm{MJ} / \mathrm{kg}$ is exempt. The EU Landfill Directive [1999/31/EC] [30] requires reductions on all biodegradable waste within 17 years to $35 \%$ of 1995 values.

The implementation of such major Directives in the EU is not a smooth process, and there are many significant difficulties due to just definitions alone. For example, the ELV Directive places responsibility for recycling and recovery on the 'manufacturers', but car companies can claim that they completely subcontract out the manufacturing and only assemble the parts. Although ASR contains organic materials that have biochemical activity, it is not generally considered biodegradable. The calorific content of ASR can vary greatly depending on the exact shredding and separation processes used - and can be easily modified to accommodate shrewd positioning. Confusion, disagreement and lobbying over issues like these can seriously impair the smooth implementation of these Directives.

Delays in implementation have direct financial effects on businesses downstream. For example, two companies in Europe (Galoo, Salyp) and one in the USA (RPI) invested heavily in mechanical separation processes to recover material from ASR, in the 
expectation that the industry would make use of their services in the absence of any other options to meet the ELV Directive in 2006. Instead, the implementation of the Directive was delayed, the industry did not have to invest in new solutions, and two of those companies consequentially faced severe financial difficulties.

\subsection{Drivers from competing markets}

For any process to be viable, its products and services must be able to compete in the marketplace. In the case of ASR there are two important sides to this. If legislation forces ASR to be diverted from all known existing treatments, then the newly developed technologies can compete for the market value of disposing of the waste. However, if usable technologies produce recovered materials or energy of significant value, they may find that the suppliers of the SR will expect to be paid for what is now effectively a feedstock material. In countries where most of the shredding facilities are controlled by only a few companies, this is a real issue. No developer of a new technology such as pyrolysis will be able to obtain adequate financing without some indication of a guaranteed SR feedstock. However, the shredding companies effectively control it, and are now in the UK inclined to indicate that, as their SR has significant polymer content of potential energy and material value, the SR itself has an intrinsic, non-negative value. They do not wish to pay a gate fee, and instead will be expect to be paid for the SR albeit after some pre-processing. 
This situation is more complex due to the fact that pyrolysis is not the only option for achieving the ELV Directive targets, nor for avoiding the high landfill disposal costs. SR contains a mixture of polymers, some of which are high-performance, and if successfully recovered could compete against international markets for recycled polymers and foams. Similarly, SR has the potential to be processed (without pyrolysis) in cement [52], to replace fuel for cement kilns $[42,43,45]$ and to contribute to metals industries as fuel and steel [45]. In these cases, its value is related to the current value of the materials or fuels it is replacing. And SR certainly has the potential to provide energy in various forms, which has a value that is locally determined depending on the different energy requirements of each country and local costs of competing fuels.

These factors and drivers clearly influence each other. However, in the middle of this already complex landscape there are further rogue factors. For example, the Landfill Directive requires most of the ELV recovery to be via materials, not energy. If high calorific fuel derived from ASR is used to generate electricity, thus displacing fossil fuels, one would expect it to be considered recovery. On the other hand, regardless of the calorific value, if it is incinerated or similarly thermally processed with inefficient conversion, one would not expect it to be credited as recovery. The shredder operators will wish to make the most profit regardless; the car manufacturers, who are considered responsible for the ELV recovery overall, will be more keen to ensure statutory targets are met. If the shredder operators go their own way, the car manufacturers would be within their rights to require ELVs of the future to only be processed at their own facilities, cutting out the shredding industry. Potential scenarios like this have 
contributed to the stakeholders withholding investment funds or making decisions on specific ways forward. It is not surprising in such circumstances that processes are not developed; it is not even clear to the main stakeholders which process types they should be focussing on.

To further complicate matters, the landscape keeps changing. In the UK, all facilities using thermal processes on wastes must be licensed with the Environment Agency. At the moment, this means that even diesels produced from, e.g. SR waste or polymer waste, are still considered waste and any vehicle using such diesel is required to be specially licensed for processing waste. Not only is this a hindrance to the development of an otherwise useful solution, it also introduces extra uncertainty to all other solutions. This is because, if legislation is suddenly changed to allow easy use of SR-derived diesel, any alternative solutions set up in the meantime will be threatened. In such an unstable market situation, banks are reluctant to invest, as are the major stakeholders.

\section{Conclusion}

There are technical, legislative, commercial and financial drivers affecting the landscape for ASR options, and all of these interact. In different countries these have different overall balances and effects. In California SR has been deemed to be hazardous waste with heavy financial consequences. In Japan, where landfill is running out but the related industries and the government work closely together, thermal processes have already been developed to commercial and semi-commercial stages to treat SR. In Europe the ELV Directive is beginning to put significant pressure on all stakeholders to develop a 
solution. However, there are several other drivers which move the stakeholders in different directions, resulting in no unity of vision for a joint way forward and lack of stability causing high risk for independent investments in specific processes.

In addition to the complex and changing drivers, it is clear that the SR waste stream itself is so variable that it cannot be assumed that processes developed in one place are suitable for waste streams produced elsewhere. In this paper summaries of data critical to the planning of new processes are provided, alongside new data. They show such wide variation that it is suggested it would be easier to develop processes optimised for local combinations of well characterised waste streams on a small-medium scale. They may prove to be as viable as large scale systems which would have to deal with much more variation in SR characteristics.

For larger scale processes, there is no clear emerging indication as to which type the various stakeholders want. Although there is now growing information and knowledge on the suitability of different technological processes and their relative strong and weak points, the stakeholders are not able to indicate which parameters they want optimised because of the changing drivers influencing their decisions. Should they focus on energy production, waste minimisation or material recovery? In the absence of a clear indication of design parameters, it is not surprising that no viable processes have been developed except in Japan where the government clarified the situation and rallied the stakeholders. In other countries stakeholders with tangential agenda are having difficulty working 
together in a scenario where the relative merits of various solutions is still constantly changing; such is the current situation in Europe. 


\section{References}

[1]. T. Malkow, Waste Manag. 24(2004). 53.

[2]. A. Porteous, Appl. Energy. 70(2001). 157

[3]. M.R. Johnson and M.H. Wang, Proc. Inst. of Mech. Eng., Part D: J. of Auto. Eng. 216(2002). 723

[4]. S. Robson and T.C. Goodhead, J. Mater. Process. Tech. 139(2003). 327.

[5]. D.L. Caputo, J. Env. Perm. 4(1995). 51

[6]. L. Borjeson, G. Lofvenius, M. Hjelt, S. Johansson, and S. Marklund, Waste Manag. Res. 18(2000). 358

[7]. S. Galvagno, F. Fortuna, G. Cornacchia, S. Casu, T. Coppola, and V.K. Sharma, Energy Conv. Manag. 42(2001). 573.

[8]. J. Staudinger and K. Keoleian, Management of End-of_life Vehicles (ELVs) in the US. Report $N^{o}$ CSSO1-01. 2001, Center for Sustainable Systems , University of Michigan: Michigan.

[9]. C.A. Ambrose, Waste Manag. November 2000, (2000)

[10]. V. Sendijarevic, B. Pokorski, D. Klempner, and K.C. Frish. Recent Developments in Shredder Downstream separation processes and recycling options for automotive shredder residue. in Society of Automotive Engineers (SAE) International Congress and Exposition: New Plastic Applications for the Automotive Industry. 1997. Detriot: Society of Automtive Engineers.

[11]. B.E. Tonn, S.M. Schexnayder, J.H. Peretz, S. Das, and G. Waidley, J. Cleaner Prod. 11(2003). 753. 
[12]. G.R. Winslow, S.X. Lui, and S. Yester, Auto. Eng. Int. 106(1998). 78

[13]. U. Lundqvist, B. Andersson, M. Axsäter, P. Forsberg, K. Heikkila, U. Jonson, Y. Larsson, U. Liljenroth, C. Sjöberg, K. Strömberg, and M. Wendin, Design for recycling in the transport sector - future scenarios and challenges. 2004, Department of Physical Resource Theory. Chalmers University of Technology Göteborg University. Göteborg Sweden.

[14]. J. Lohse, K. Sander, and M. Wirts, Heavy metals in Vehicles II. Final Report. OKOPOL. 2001: Hamburg.

[15]. K. Sander, J. Lohse, and U. Pirntke, Heavy Metals in Vehicles. Final Report . OKOPOL. 2000: Hamburg.

[16]. J. Gearhart, D. Menke, C. Griffith, and K. Mills, Getting the Lead Out. Impacts of and Alternatives for Automotive Lead Uses. 2003, Ecology Center: Ann Arbor.

[17]. C. Collins, A. Fanning, M. Crowe, and B. Meaney, End of life vehicles in Ireland. A sectoral report. 2002, EPA, Ireland.

[18]. M. Day, J. Graham, R. Lachmansingh, and E. Chen, Resou. Conser. Recyc. 9(1993). 255.

[19]. O.T. Forton, M.K. Harder, and N.R. Moles, Resou. Conser. Recyc. 46(2006). 104.

[20]. B.J. Jody and E.J. Daniels, Hazard. Waste Hazard. Mater. 8(1991). 219.

[21]. WERG, Polymer Processing B: Towards Processing Polymers from ASR Polymer Processing. 2002, A report by the Waste and Energy Research Group, University of Brighton, commissioned by Brighton Environmental Body Ltd for the Consortium of Automotive Vehicle Recycling. . 
[22]. C.A. Ambrose, M.M. Singh, and M.K. Harder, Inst. Waste Manage. Sc. Tech. Review., (2000). 27

[23]. S.X. Lui, G.R. Winslow, S. Yester, G.P. Gromek, A. Crouch, and V. Sendijarevic, SAE Special Pub. 1342(1998). 217

[24]. E.J. Daniel, B.J. Jody, and P.V. Bonsignore, J. Resou. Manage. Tech. 20(1992). 14

[25]. D. Lanoir, G. Trouve, L. Delfosse, D. Froelich, and A. Kassamaly, Waste Manag. Res. 15(1997). 267.

[26]. M. Zolezzi, C. Nicolella, S. Ferrara, C. Iacobucci, and M. Rovatti, Waste Manag. 24(2004). 691.

[27]. I.d. Marco, B. Caballero, A. Torres, M.F. Laresgoiti, M.J. Chomón, and M.A. Cabrero, J. Chem. Tech. Biotech. 77(2002). 817

[28]. D. Mirabile, M.I. Pistelli, M. Marchesini, R. Falciani, and L. Chiappelli, Waste Manag. 22(2002). 841.

[29]. R. Rausa and P. Pollesel, J. Anal. Appl. Pyrolysis. 40-41(1997). 383.

[30]. European-Commission, Council Directive 1999/31/EC of April 261999 on the landfill of waste. 1999, Official Journal of the European Communities. L182/2.

[31]. European-Commission, Directive 2000/53/EC of the European Parliament and of the Council of 18 September 2000 on end-of-life vehicles. Official Journal of the European Communities. 2000, European Commission.

[32]. S. Das, T.R. Curlee, C.G. Rizy, and S.M. Schexnayder, Resou. Conser. Recyc. 14(1995). 265.

[33]. D. Lanoir, G. Trouve, and L. Delfosse, Waste Manag. 17(1997). 475. 
[34]. DEFRA, Depolluting End-of-Life Vehicles Guidance for Authorised Treatment Facilities. http://www.ehsni.gov.uk/pubs/publications/DepollutingELVs.pdf last accessed March 25 2006, (2003)

[35]. DEFRA, Depollution Guidance for End-of-life Vehicles over 3.5 tonnes. http://www.defra.gov.uk/environment/waste/topics/elv-depollution.pdf $\quad$ last accessed March 25 2006, (2004)

[36]. M. Day, F.T. Awadalla, and A. Lynhiavu, Environ. Tech. 15(1994). 585

[37]. WERG, Pyrolysation of shredder residue (fines). A report by the Waste \& Energy Research Group, University of Brighton, commissioned by the Brighton Environmental Body Ltd for the Consortium of Automotive Vehicle Recycling. 2002: Brighton, UK.

[38]. W. Kaminsky, B. Schlesselmann, and C.M. Simon, Polym. Degrad. Stability. 53(1996). 189.

[39]. M. Inguanzo, A. Dominguez, J.A. Menendez, C.G. Blanco, and J.J. Pis, J. Anal. Appl. Pyrolysis. 63(2002). 209.

[40]. M. Day, Z. Shen, and J.D. Cooney, J. Anal. Appl. Pyrolysis. 51(1999). 181.

[41]. P.T. Williams, Waste Treatment and Disposal. 2 nd edition ed. 2005, Chichester: John Wiley \& Sons Ltd.

[42]. B. Boughton and A. Horvath, Resou. Conser. Recyc. 47(2006). 1.

[43]. B. Boughton, Evaluation of shredder residue as cement manufacturing feedstock. 2006, California Environmental Protection Agency, USA.

[44]. J.K. Fink, J. Anal. Appl. Pyrolysis. 51(1999). 239.

[45]. O. Williams-Thorpe, P.J. Potts, and P.C. Webb, J. Archaelo. Sc. 26(1999). 215. 
[46]. P.J. Wood, California's Automobile Shredder Waste Initiative. Draft Report. 2002, Department of Toxic Substances Control: Sacremento.

[47]. AEAT, Analysis of fragmentiser residue. Report to the Environment Agency AEAT/ENV/R1846. UK, (2005)

[48]. C. Heermann and F.J. Schwager, Worldwide directory of gasification \& pyrolysis processes and suppliers. Part 2, Listing of suppliers and licensees. Part 1, A-Z of gasification \& pyrolysis. Juniper Consultancy Services, 2002., (2002)

[49]. C. Heermann, F.J. Schwager, and K.J. Whiting, Pyrolysis \& gasification of waste : a worldwide technology \& business review Vol.1, Markets \& trends. Juniper Consultancy Services, 2000.217pp, (2000)

[50]. C. Heermann, F.J. Schwager, and K.J. Whiting, Pyrolysis \& gasification of waste : a worldwide technology \& business review . Vol.1, Markets \& trends. Juniper Consultancy Services, 2000. 183p, (2000)

[51]. European-Commission, European Commission. Directive 2000/76/EC of the European Parliament and of the Council of 4 December 2000 on the incineration of waste. Official Journal of the European Communities, (2000)

[52]. J. Pera, J. Ambroise, and M. Chabannet, Cement Concr. Res. 34(2004). 557.

[53]. K. Kakimoto, Y. Nakano, T. Yamasaki, K. Shimizu, and T. Idemitsu, Appl. Energy. 79(2004). 425.

[54]. C.A. Ambrose, R. Hooper, A.K. Potter, and M.M. Singh, Resou. Conser. Recyc. 36(2002). 309.

[55]. S. Sakai, S. Urano, and H. Takatsuki, Waste Manag. 20(2000). 241.

[56]. J.J.H. Bilbrey, J.W. Sterner, and E.G. Valdez, Conser. Recyc. 2(1978). 219.

[57]. S.C. Saxena, N.S. Rao, A. Rehmat, and M.C. Mensinger, Energy. 20(1995). 877.

[58]. C. Pasel and W. Wanzl, Fuel Process. Tech. 80(2003). 47. 
[59]. C. Roy and A. Chaala, Resou. Conser. Recyc. 32(2001). 1.

[60]. M. Day, J.D. Cooney, and Z. Shen, J. Anal. Appl. Pyrolysis. 37(1996). 49.

[61]. Z. Shen, M. Day, J.D. Cooney, G. Lu, C.L. Briens, and M.A. Bergougnou, Canadian J. Chem. Eng. 73(1995). 357.

[62]. G. Trouve, A. Kauffmann, and L. Delfosse, Waste Manag. 18(1998). 301

[63]. K.M. Attar, B.S. Tawabini, E.R. Pambid, and M.A. Abdel-Aal, Waste Manag. 11(1991). 283.

[64]. B.J. Jody, E.J. Daniels, P.V. Bonsignore, and N.F. Brockmeier, J. Metals. 46(1994). 40 
Table 1: Material Compositions (\%)of Shredder Residue reported

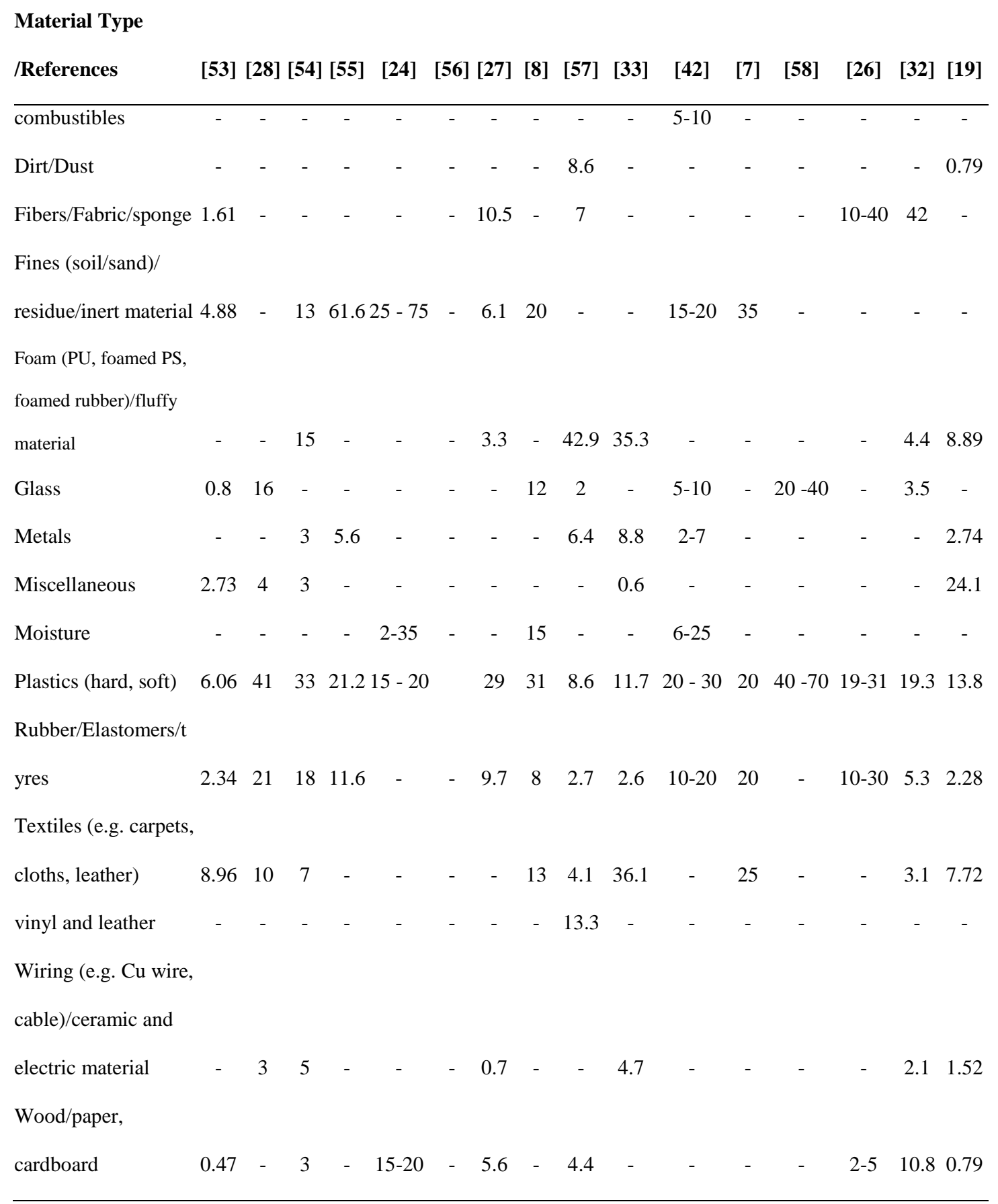


Table 2: Reported ASR and SR heating values reported

\begin{tabular}{ccc}
\hline Fraction type & $\begin{array}{c}\text { Higher Heating } \\
\text { Value (MJ/kg) }\end{array}$ & Refs \\
\hline Solid residues & $6.7-30.7$ & {$[6]$} \\
26 & {$[59]$} \\
19 & {$[13]$} \\
$4.4-18.2$ & {$[25]$} \\
$39.9-41.1$ & {$[26]$} \\
1.7 & {$[27]$} \\
16.7 & {$[7]$} \\
28.3 & {$[28]$} \\
\hline liquids & $28.8-34.3$ & {$[26]$} \\
\hline
\end{tabular}


Table 3: Reported relative distribution of ASR pyrolytic products (solids, liquids and gases)

\begin{tabular}{|c|c|c|c|c|c|}
\hline & $\begin{array}{c}\text { Temperature }^{\circ} \\
\text { C }\end{array}$ & $\begin{array}{c}\text { Solid } \\
\%\end{array}$ & $\begin{array}{c}\text { Liquid } \\
\%\end{array}$ & $\begin{array}{c}\text { Gas } \\
\%\end{array}$ & Reference \\
\hline $\begin{array}{l}\text { General } \\
\text { pyrolysis }\end{array}$ & 550 & 30 & 40 & $\begin{array}{c}12(18 \% \\
\text { water })\end{array}$ & [7] \\
\hline \multicolumn{5}{|l|}{ pyrolysis/Tubul } & [26] \\
\hline \multirow[t]{5}{*}{ ar reactor } & 500 & 47.5 & 35 & 7.7 & \\
\hline & 600 & 37.5 & 43 & 5.8 & [26] \\
\hline & 700 & 33 & 55 & 8.5 & [26] \\
\hline & 800 & 25 & 58 & 12.2 & [26] \\
\hline & $500-800$ & $\sim 35$ & 40 & 20 & [58] \\
\hline $\begin{array}{l}\text { Commercial } \\
\text { screw kiln }\end{array}$ & 500 & 43 & 31 & 26 & [60] \\
\hline Rotary Kiln & & & & & [7] \\
\hline \multirow[t]{3}{*}{ pyrolysis } & 550 & 59.28 & 19.52 & 4.23 & \\
\hline & 600 & 44.55 & 32.62 & 9.04 & [7] \\
\hline & 680 & 43.57 & 20.07 & 13 & [7] \\
\hline $\begin{array}{l}\text { Vacuum } \\
\text { pyrolysis }\end{array}$ & $496-536$ & 52.5 & 27.7 & $\begin{array}{c}6.6(13.3 \% \\
\text { water })\end{array}$ & [59] \\
\hline \multicolumn{5}{|l|}{ pyrolysis } & [27] \\
\hline (Heavy ASR) & 500 & 39.4 & 29 & 31.6 & \\
\hline $\begin{array}{l}\text { Autoclave } \\
\text { pyrolysis (Light }\end{array}$ & & & & & [27] \\
\hline ASR) & 500 & 63.6 & 10.3 & 26.1 & \\
\hline Currie point & & & & & [58] \\
\hline pyrolyser & $500-950$ & $\sim 10$ & $\sim 10$ & $\sim 75$ & \\
\hline \multirow[t]{5}{*}{ Fast pyrolysis } & $700-850$ & $58-68$ & $4-12$ & $13-23$ & [61] \\
\hline & 500 & 55 & 25.7 & 5.8 & [26] \\
\hline & 600 & 52.3 & 30 & 11.5 & [26] \\
\hline & 700 & 39 & 24.2 & 24.1 & [26] \\
\hline & 800 & 37 & 21.8 & 34 & [26] \\
\hline
\end{tabular}


Table 4: Reported metal and chlorine levels in ASR pyrolysis solid residues: fines fraction

\begin{tabular}{|c|c|c|c|}
\hline Element & [7] & [59] & {$[60]$} \\
\hline & $\mathrm{wt} \%$ & $\mathrm{wt} \%$ & $\mathrm{wt} \%$ \\
\hline $\mathrm{Pb}$ & $0.30-0.35$ & $0.25-0.49$ & $0.56-0.25$ \\
\hline $\mathrm{Zn}$ & $0.43-0.67$ & $1.08-1.58$ & $0.61-1.62$ \\
\hline $\mathrm{Cd}$ & $0.003-0.007$ & $55-84$ & $0.006-0.003$ \\
\hline $\mathrm{Cr}$ & $0.015-0.020$ & $117-315$ & $0.05-0.02$ \\
\hline $\mathrm{Cu}$ & $0.72-4.88$ & & $0.27-6.78$ \\
\hline $\mathrm{Ni}$ & $0.01-0.015$ & $190-1640$ & - \\
\hline $\mathrm{Fe}$ & $2.36-2.7$ & $7.24-14.4$ & - \\
\hline $\mathrm{Al}$ & $0.62-4.88$ & $0.99-1.85$ & - \\
\hline $\mathrm{Hg}$ & $0.0002-0.0004$ & - & - \\
\hline Co & $0.18-4.08$ & $102-149$ & - \\
\hline $\mathrm{Ca}$ & - & $3.84-9.17$ & - \\
\hline V & - & $24-50$ & - \\
\hline Mn & - & $512-1990$ & - \\
\hline
\end{tabular}


Table 5: Chlorine levels reported in shredder residue (raw)

\begin{tabular}{|c|c|}
\hline Chlorine & Reference \\
Concentration (wt \%) & \\
\hline 0.54 & {$[7]$} \\
\hline 2.1 & {$[58]$} \\
\hline 0.2 & {$[26]$} \\
\hline 3.7 & {$[62]$} \\
\hline 3.5 & {$[25]$} \\
\hline 0.31 & {$[52]$} \\
\hline $2-5$ & {$[58]$} \\
\hline
\end{tabular}


Table 6: Reported levels of metal contamination in (A)SR (raw)

\begin{tabular}{|c|c|c|c|c|c|c|c|c|c|c|c|c|}
\hline $\mathbf{P b}$ & $\mathrm{Zn}$ & $\mathrm{Cu}$ & $\mathrm{Fe}$ & $\mathrm{Cr}$ & $\begin{array}{c}\text { Metal } \\
\text { Cd }\end{array}$ & As & Al & $\mathbf{H g}$ & Mn & $\mathbf{N i}$ & Units & Ref. \\
\hline 0.19 & 0.97 & 1.67 & - & 0.09 & 0.003 & - & - & - & & - & $\mathrm{Wt} \%$ & [36] \\
\hline 0.7 & 0.8 & 2.1 & 13.2 & 0.7 & - & - & 2.1 & - & 0.1 & 0.4 & $\mathrm{Wt} \%$ & [25] \\
\hline $\begin{array}{c}0.21- \\
0.93\end{array}$ & $\begin{array}{c}0.53-0 \\
14\end{array}$ & $\begin{array}{c}0.28- \\
0.16\end{array}$ & $\begin{array}{c}0.26- \\
0.14\end{array}$ & $\begin{array}{c}0.00002 \\
- \\
00000.8\end{array}$ & $\begin{array}{c}0.0022- \\
0.0042\end{array}$ & - & $\begin{array}{c}0.16- \\
0.86\end{array}$ & - & & - & $\mathrm{Wt} \%$ & $\begin{array}{l}\text { (ASR) } \\
{[6]}\end{array}$ \\
\hline $\begin{array}{c}0.16- \\
0.32\end{array}$ & $\begin{array}{c}1.0- \\
4.4\end{array}$ & $\begin{array}{c}0.026- \\
0.210\end{array}$ & $\begin{array}{c}6.7- \\
37\end{array}$ & $\begin{array}{c}0.00017 \\
- \\
0.00068\end{array}$ & $\begin{array}{c}0.0019- \\
0.0034\end{array}$ & - & $\begin{array}{c}0.65- \\
2.21\end{array}$ & - & & - & $\mathrm{Wt} \%$ & $\begin{array}{l}(\mathrm{SR}) \\
{[6]}\end{array}$ \\
\hline $\begin{array}{c}0.12- \\
0.61 \\
(0.28)\end{array}$ & $\begin{array}{c}0.37- \\
1.53(1)\end{array}$ & $\begin{array}{c}0.256- \\
2.39\end{array}$ & - & $\begin{array}{c}0.02- \\
0.04\end{array}$ & $<0.01$ & - & - & - & & - & $\mathrm{Wt} \%$ & [18] \\
\hline $\begin{array}{c}0.09- \\
5.3\end{array}$ & $\begin{array}{c}0.058- \\
1.9\end{array}$ & $\begin{array}{c}0.043- \\
5.3\end{array}$ & - & - & - & - & - & 0.00007 & & - & $\mathrm{Wt} \%$ & [46] \\
\hline $\begin{array}{c}0.224- \\
0.645\end{array}$ & $\begin{array}{c}0.72- \\
0.94\end{array}$ & $\begin{array}{c}0.62- \\
3.90\end{array}$ & $\begin{array}{c}13.0- \\
13.2\end{array}$ & $\begin{array}{c}0.023- \\
0.066\end{array}$ & $\begin{array}{c}0.005- \\
0.0065\end{array}$ & - & $\begin{array}{c}1.05- \\
2.10\end{array}$ & - & & $\begin{array}{l}0.018- \\
0.093\end{array}$ & $\mathrm{Wt} \%$ & [59] \\
\hline 0.1 & 1.08 & 0.82 & 43.2 & 0.03 & - & - & - & - & & - & $\mathrm{Wt} \%$ & [64] \\
\hline 0.2 & 1.9 & 1.2 & 25.7 & 0.08 & - & - & - & - & & 0.07 & $\mathrm{Wt} \%$ & [28] \\
\hline 0.79 & 0.79 & 0.52 & 8.41 & $<0.02$ & 0.12 & - & - & - & 3.63 & 0.67 & $\mathrm{Mg} / \mathrm{L}$ & [63] \\
\hline $\begin{array}{c}0.26- \\
1.93\end{array}$ & - & $\begin{array}{c}0.22- \\
0.78\end{array}$ & $\begin{array}{c}0.9- \\
15.7\end{array}$ & $<0.01$ & $\begin{array}{c}0.004- \\
0.007\end{array}$ & $\begin{array}{c}0.9- \\
3.0\end{array}$ & - & $1.0-2.1$ & & - & $\mu \mathrm{g} / \mathrm{L}$ & [53] \\
\hline
\end{tabular}


Figure 1. Schematic of the PKA Process

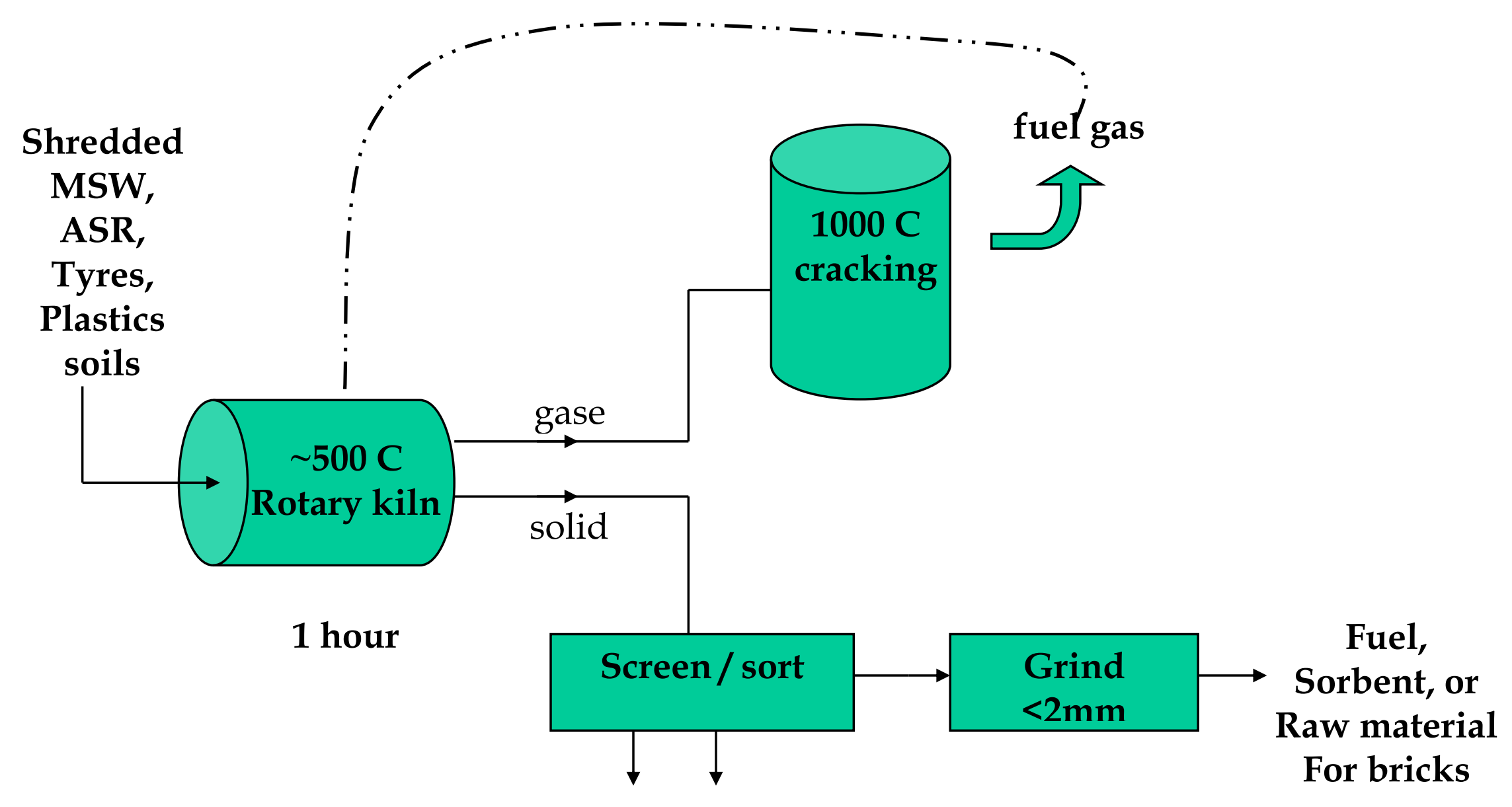

Fe \& non-Fe metals

OR... vitrify char at $1400 \mathrm{C}$, granulate $<1 \mathrm{~mm}$ and use for cement 
Figure 2. Schematic of the Pyrolmelt Process (Lurgi Entsorgung)

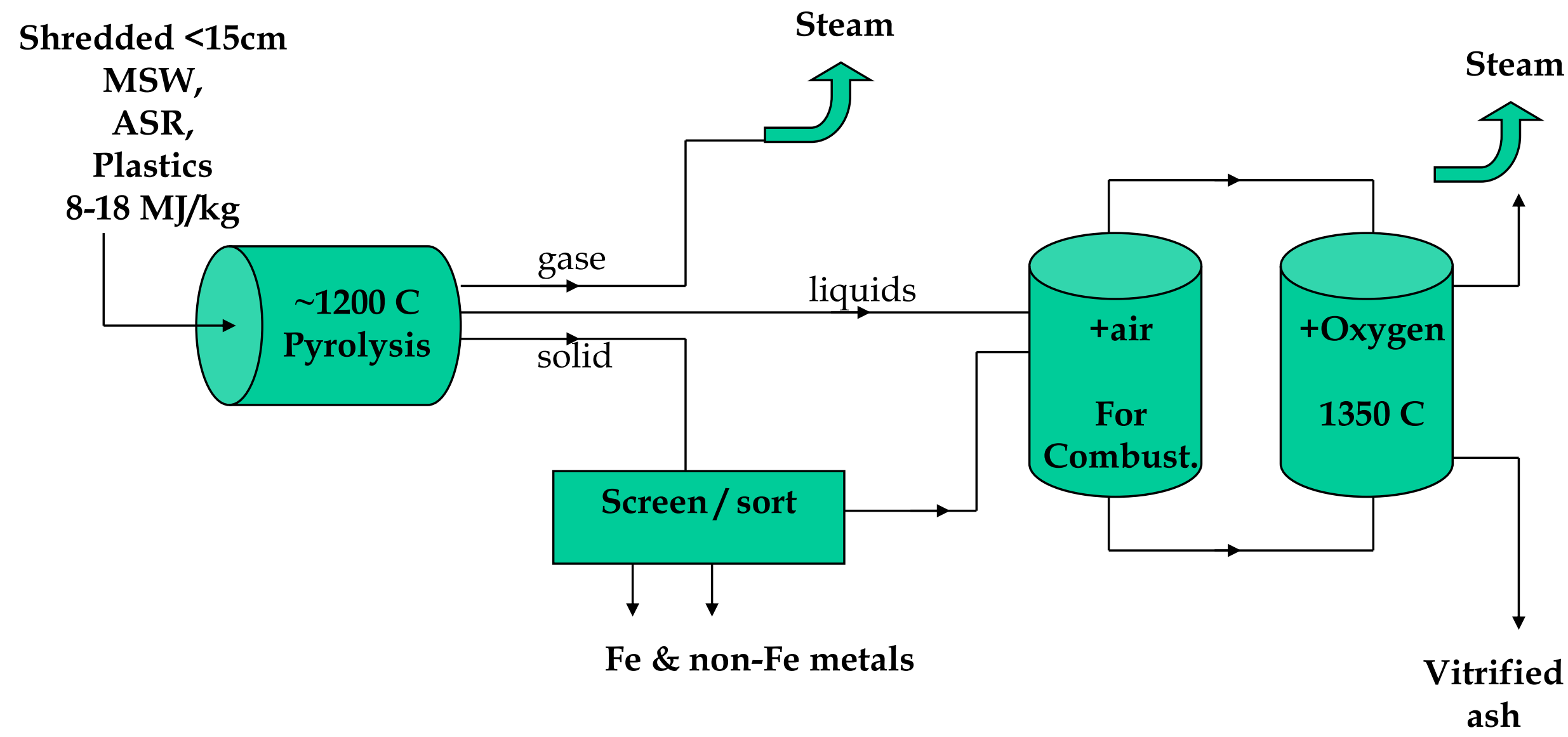


Figure 3. Schematic of the TWR Process (Takuma) (Siemens; Schwel-Brenn $\rightarrow$ TWR / Mitsui Processes)

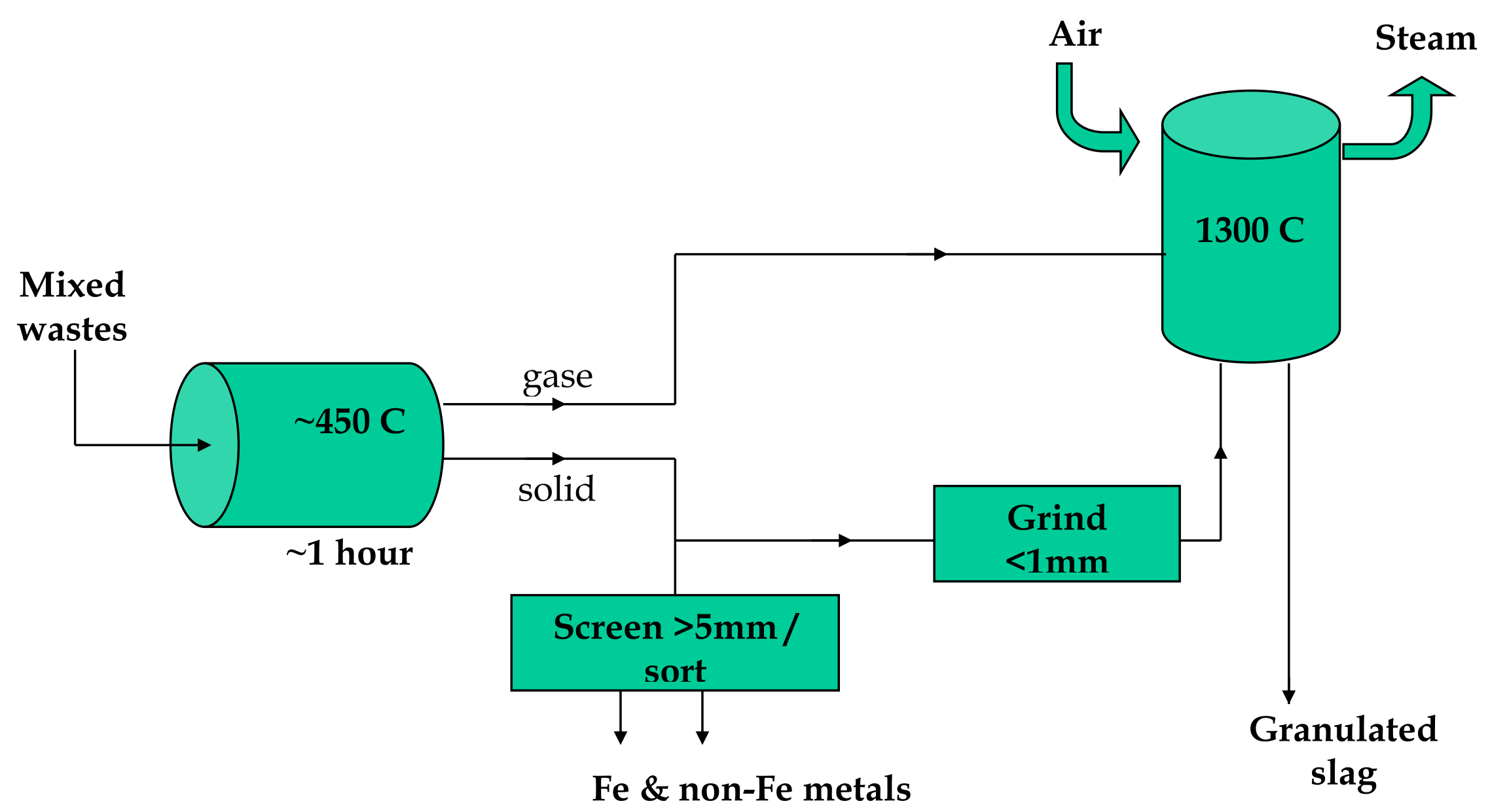


Figure 4. Schematic of the Schwarze Pumpe Process (SVZ ;Global Energy)

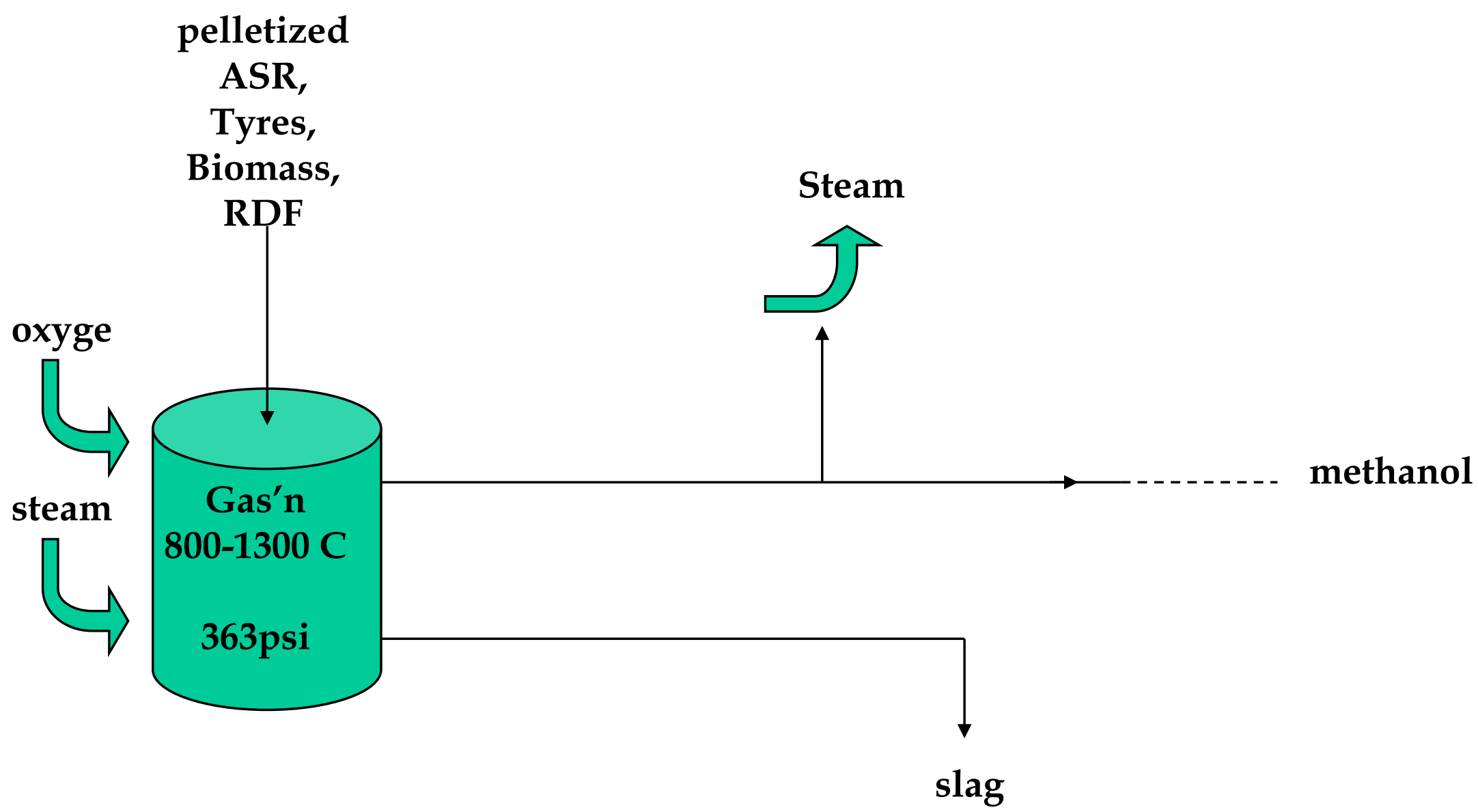

